\title{
Community Service on the Fish Cultivator Group in Pakisan Village, Kubutambah Sub-district, Buleleng Regency
}

\author{
I Made Kawan ${ }^{1}$; Dewa Sadguna ${ }^{2}$; Ni Made Darmadi ${ }^{3}$ \\ \{imadekawan@yahoo.co.id\} \\ 1,2,3. Lecturer in the Faculty of Agriculture, Warmadewa University
}

\begin{abstract}
The appropriate use of technology such as "Net Grider" to separate the size (sorting) of tilapia fish is applied to the "Mina Sakti" Fish Cultivation Group by the Community Service (PkM) partners located in Pakisan Village, Kubutambah Sub-district, Buleleng Regency. The constraint of the partner group is associated with the complaints from buyers such as due to death of fish when sorting the seeds, inability to understand the importance of the post seed harvest stage, unable to determine the separator tool (Net Grider) and not knowing the right utilization method. Therefore, the PkM aims to ensure that $100 \%$ of the partner group members understand the importance of post seed harvest, with 95\% skilled in using "Net Grider" with an increase in the sales turnover of seeds by $80 \%$. The method used to implement the PkM is through counseling and training on the application of fish seed size sorting or selection technology in the post seed harvest stage of tilapia hatchery business using the Net Grider. From the program implemented, all participants $(100 \%)$ in the counseling and discussion groups have the ability to understand the importance of post-harvest and use of tools. The practice of using tools produced tilapia seeds that are healthy with the ability to increase sales turnover without any complaints from buyers.
\end{abstract}

Keywords : Sorting Method, Net Grider, Tilapia Seed.

\section{Pendahuluan}

Kegiatan PkM ini mengambil obyek pada Kelompok Pembudidaya Ikan (Pokdakan) "Mina Sakti" di Desa Pakisan,Kecamatan Kubutambahan, Kabupaten Buleleng. Kelompok mitra ini berkegiatan pada pembenihan ikan Nila, benih yang dihasilkan banyak mengalami kematian pada saat melakukan panen dan pada saat melakukan sortasi atau seleksi ukurannya. Selain itu daya hidup benih yang dihasilkan hasil seleksi masih rendah karena perlakukan panen dan sortasi memerlukan waktu yang lama sehingga ikan sebagian stres dan mengalami kematian, hal ini akan menurunkan kuantitas dan kualitas benih yang didapatkan. Dampak dari kelemahan ini akan mengurangi kemampuan kelompok untuk memenuhi permitaan benih 
yang terus meningkat dari para pembudidaya ikan konsumsi dalam Kantong Jaring Apung (KJA) di Danau Batur, Kintamani, Bangli, baik secara kualitas maupun kuantitasnya.

Kelompok mitra selama ini teknologi sortasi benih yang digunakan masih bersifat tradisional yang belum mampu memenuh ijumlah dan mutu benih ikan sesuai harapan (optimal), sehingga mempengaruhi omzet usaha mereka yang masih perlu ditingkatkan. Mengingat permintaan akan benih ikan ini tidak pernah terpenuhi maka produksi benih ikan nila yang dihasilkan kelompok mitra masih tetap diterima oleh para pembeli dari pembudidaya pembesaran pada KJA di danau Batur. Namun demikian kelompok mitra tetap berupaya memproduksi benih dan meningkatkan kuantitas dan kualitas benih ikan nila yang dihasilkan untuk mempertahankan keberlanjutan dan perkembangan usaha kedua belah pihak. Oleh karena itu kelompok mitra sangat tertarik untuk menerapkan teknologi tepat guna terutama cara sortasi atau seleksi ukuran benih dengan menggunakan "Grider Jaring" sebelum benih dikirim ke pelangannya.

Kegiatan PkM ini diharapkan (a) semua anggota kelompok mitra (100\%) memiliki tingkat pemahaman terhadap pentingnya pasca panen benih; (b) keterampilan cara panen benih dan sortasi atau seleksi ukuran benih ikan pada kelompok mitra meningkat sampai 95\%, dan (c) omzet penjualan benih kelompok mitra akan meningkat menpapai $80 \%$.

\section{Metode Penelitian}

Metode yang digunakan dalam pelaksanaan kegiatan PkM adalah melalui beberapa tahapan:

1) Tahap persiapan meliputi melakukan survei lokasi dan melakukan kesediaan kelompok sebagai mitra

2) Tahap Pelaksanan terdapat dua kegiatan yaitu (a) melakukan penyuluhan dan diskusi terhadap permasalahan kelompok tentang pentingnya tahap pasca panen benih ikan nila khususnya sortasi dengan memperkenalkan teknologi tepat guna menggunakan alat "Grider Jaring" dan (b) melakukan pelatihan dan praktek menggunakan alat sortasi benih ikan nila dengan alat "Grider Jaring"

3) Tahap monitoring dan evaluasi kegiatan PkM dilaksanakan melalui pendampingan dan pemantauan terhadap keberasilan benih yang telah dilakukan sortasi sampai dilakukan penjualan

\section{Hasil Kegiatan}

Kegiatan tahap persiapan ini memerlukan waktu paling banyak dari rangkaian proses PkM yang dilakukan, yaitu mulai merancang dan pemesanan alat "Grider Jaring" sampai persiapan pemasangan alat agar dapat digunakan untuk memisahkan ukuran yang sesuai dengan ukuran benih yang diinginkan dari kebutuhan pasar benih bagi para pembudidaya ikan Keramba Jaring Apung (KJA) di Danau Batur Kintamani.

Kelompok mitra mempersiapkan bahan-bahan seperti patok bambu, benih ikan dan peralatan yang akan digunakan dalam pelatihan dan praktek menggunakan alat "Grder Jaring" 
yang akan digunakan untuk memisahkan ukuran ikan nila yang akan di panen. Alat "Grider Jaring” yang dipersiapkan oleh kelompok mitra dapat dilihat pada Gambar 1.

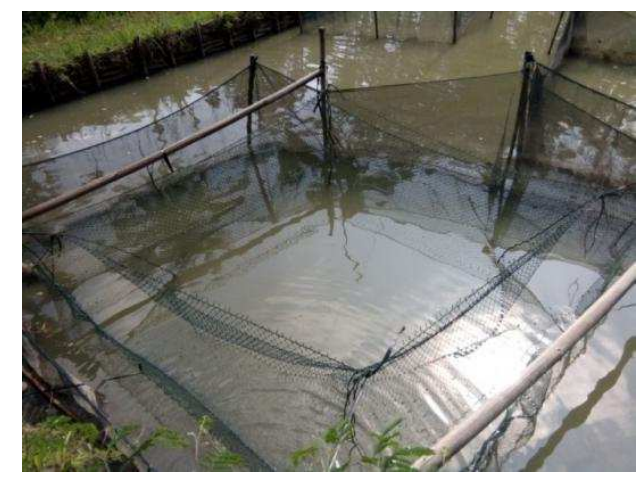

Gambar 1. Alat Grider Jaring

Selama proses persiapan, anggota kelompok mitra sekalisus diberikan pemahaman teori praktek tentang prinsip kerja alat yang diharapkan dapat lebih lancar menggunakan alat Grider Jaring yang akan dipakai praktek dalam pelatihan agar dapat tersosialisasikan kepada masyarakat, baik yang sudah melakukan usaha pembenihan ikan nila maupun yang belum serta teknologi ini diketahui oleh kelompok diluar mitra agar teknologi pasca panen benih ikan nila menggunakan Grider Jaring berkembang di desa Pakisan dan desa-desa sekitarnya.

Hasil pertemuan dalam penyuluhan (Gambar 2.) yang telah dilakukan dimana kelompok mitra sangat setuju (100\%) melaksanakan teknologi tepat guna saat panen menggunakan Grider Jaring untuk menyeleksi ukuran benih ikan nila sebelum dipasarkan atau dikirim kepada para pembudidaya ikan dalam KJA di Danau Batur. Para pembenih ikan nila pada kelompok mitra akhir-akhir ini mengalami kendala baru dengan adanya hama burung bangau dan kepiting perusak pematang yang dapat merugikan para pembenih sebelum ikan di lakukan pemanenen.

Tim pengabdian sebagai Narasumber memberikan solusi untuk mengatasi hama burung yaitu di atas kolan diberikan tali senar atau benang yang diikatkan pada tali ris dengan jarak $10-20 \mathrm{~cm}$, benang yang terpasang ini akan menjerat hama burung bangau apabila menyentuh tali yang terpasang, terjeratnya burung ini akan memberikan ketakutan burung lain untuk mencari ikan pada kolam para pembudidaya. Permasalahan lain adalah adanya kepiting perusak pematang yang muncul akhir-akhir ini, kendala ini diberikan solusi dengan mengurangi jumlah populasi kepiting yaitu (1) melakukan penangkapan dan diolah menjadi menu masakan yang mempunyai nilai ekonomis, (2) dan melakukan penelitian tentang penghentian fungsi organ reproduksi kepiting melalui pemberian pakan sehingga diharapkan populasi keping dapat berkurang. Peledakan populasi kepiting yang terjadi ini tidak saja merugikan para pembudidaya ikan, akan tetapi para petani padi dan subak akan dirugikan karena akan terjadi kebocoran dalam sistem pengairannya. 


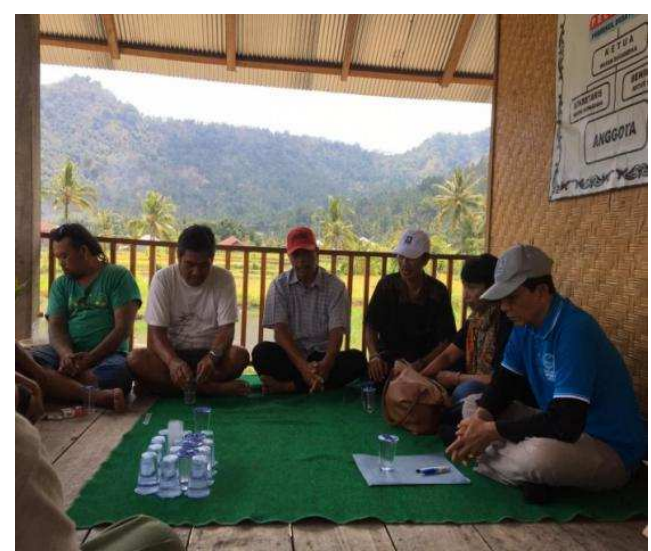

Gambar 2. Dokumen foto penyuluhan

Pelatihan dan Praktek penggunaan alat Grider Jaring, kelompok mitra sudah melakukan persiapan dan ikan-ikan yang akan dipisahkan di tangkap dengan menggunakan alat Jaring Gelar. Teknologi tepat guna dengan penggunaan Jaring Gelar untuk menangkap benih-benih ikan nila yang akan dipisahkan merupakan salah satu cara panen yang sangat baik (Gambar.3), cara panen ini diharapkan ikan sedikit yang mati dan ikan yang ditangkap akan sehat baik dalam pengiriman maupun pembesaran dalam KJA di Danau Batur.

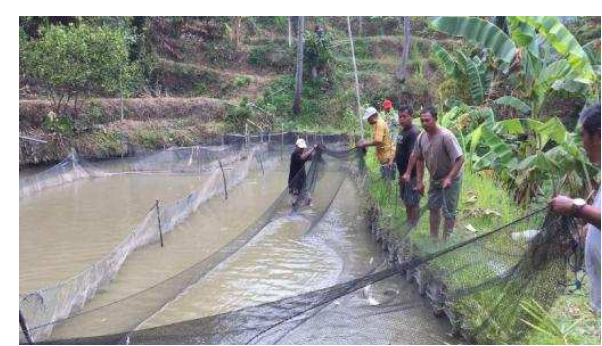

Gambar 3. Panen Benih dengan Jaring Gelar

Praktek yang dilakukan pada kelompok mitra menginginkan benih yang diperoleh sesuai dengan permintaan ukuran benih dari para pembudidaya di Danau Batur yaitu ukuran benih 5$7 \mathrm{~cm}, 7-9 \mathrm{~cm}$ dan 9-12 cm. Penggunaan Grider Jaring ini akan dapat memisahkan ukuran ikan yang dikehendaki dengan cepat dan ikan yang di panen tidak akan kelelahan atau stres sehingga ikan yang akan dikirim dapat mencapai kelulushidupan 100\% atau tidak ada kematian (Gambar4). Selain itu ikan yang ditebar dalam KJA tidak memerlukan waktu lama untuk beradaptasi dan dapat tumbuh dengan cepat. Hasil praktek tetap diamati keberhasilannya dan kelompok mitra didampingi terhadap kendala-kendala yang ada guna dapat meningkatkan omset penjualannya. 


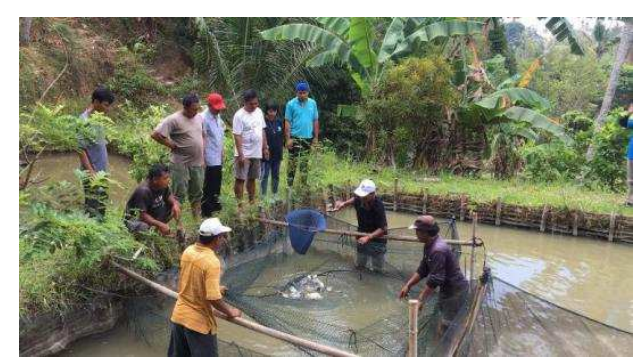

Gambar: 4 Penggunaan Grider Jaring 100\% benih ikan nila hidup

\section{Kesimpulan}

Pelaksanaan kegiatan PkM yang telah dilakukan pada kelompok Mitra Mina Sakti di Br. Tegehe Desa Pakisan Kabupaten Buleleng dapat disimpulkan sebagai berikut:

1) Kelompok mitra sangat serius dan antusias mengikuti penyuluhan dan diskusi dimana semua anggota ( $100 \%$ memahami pentingnya teknologi pasca panen benih ikan nila

2) Pelatihan dan praktek menggunakan alat "Grider Jaring" menghasilkan $100 \%$ benih ikan nila yang disortasi dapat hidup sehat

Meningkatnya jumlah benih yang hidup sehat yang dihasilkan kelompok mitra dapat meningkatkan omset penjualan

\section{References}

[1] Anonim., 2017. Direktorat Riset dan Pengabdian Masyarakat, Direktorat Jendral Penguatan Riset dan Pengembangaan, Kementerian Riset. Teknologi, dan Pendidikan Tinggi, RI. 2017. Panduan Pelaksanaan Penelitian dan Pengabdian kepada Masyarakat di Perguruan Tinggi, Edisi XI, Jakarta.

[2] Khairuman dan Amri, K. 2003. Budidaya Ikan Nila Secara Intensif. Agromedia Pustaka.

[3] Listiarini. 2017. Paper Keramba Jaring Tancap. Listia07.blogspot. in/2017/09/paper-karamabjaring-tancap.htm?m=1 